\title{
Principles of development of agricultural consumer cooperation in the agricultural sector of Russia
}

\author{
Alexander Klimenko ${ }^{1}$, Artem Grinko ${ }^{1}$, and Marina Kholodova ${ }^{1, *}$ \\ ${ }^{1}$ Federal Rostov Agrarian Scientific Center (FSBSI FRARC), Rassvet, Rostov region, Russia
}

\begin{abstract}
The authors conducted research to identify and systematize the principles of development of agricultural consumer cooperation in the agricultural sector of Russia. In particular, it was noted that the agrarian reforms, the processes of integration of the country into the global economic space and the struggle for leadership in the global agri-food market led to the emergence of new forms of economic interaction, including agricultural cooperation, and forced a new perception of the principles of development of agricultural producers traditional for the socialist economy. In this paper, special attention is paid to the principles of state regulation of the activities of small businesses. Within the framework of the presented scientific development, the abovementioned principles were refined taking into account the new economic reality and supplemented with the principles of the project approach in management. The proposed new managerial tools of state regulation of the agricultural sector based on the principles of the design approach will help to focus the efforts of governments at all levels to achieve concrete results in the framework of the National project "Creation of system of support of farmers and development of agricultural consumer cooperation", but also transfer to small businesses in the advanced level of development.
\end{abstract}

\section{Introduction}

Systematic and sustainable process of expanded reproduction in the agricultural sector of the economy, affecting all forms of development of economic relations in agriculture, involves the formation of a single, universal theories, laws, rules, norms of economic activity, which can act in accordance with the internal logic and functioning of the multiculturalism in the village.

Market structural transformation of the agricultural sector of Russia has allowed us to build and develop three main forms of management in the agricultural sector of agriculture

\footnotetext{
* Corresponding author: kholodovama@rambler.ru
} 
- agricultural organizations, peasant (farmer) farms and private farms, the stability of which is determined by connecting the basic factors of production: land, labor, capital, entrepreneurial skills and information, and the flexibility and timely response to the changing trends of civilization and scientific and technological transformations, integration processes $[1,2,3]$.

Currently, the main forms of management in the agro-industrial complex operate in chaotic, spontaneous market conditions, characterized by imperfection of regulatory legislation and customs and tariff regulation, personnel and logistics policies, unbalanced relations in the distribution of state support funds, as well as with financial and credit, tax, innovation and investment, and insurance spheres, which do not ensure the development of expanded reproduction in agricultural sectors $[4,5,6]$.

The current imbalance between the interests of key participants in the production process in agriculture requires substantiation of new approaches to the organization of economic activity for the most efficient agricultural production, based on objective reality, based on certain scientific principles identified in the process of developing the theory and methodology of guided development of the agrarian structure of the Russian Federation, as well as the principles of flexible mechanism of state regulation of agricultural producers as a key tool, stimulating the development of multiculturalism in rural areas.

\section{Results}

The modern multi-layered economy of agriculture is a complex socio-economic system and requires the formation of unified principles of managerial interaction, covering the entire set of production and economic relations and connections on a large scale.

Over the past fifteen years, the country's agriculture has seen significant transformational changes, both related to the reform of property relations, the choice of national priorities, the reorganization of economic entities, and the integration of the country into the global economic space, the struggle for leadership in the global agri-food market. These trends led to the emergence of new forms of economic interaction and forced a new perception of the principles of development of agricultural producers of various forms of management, traditional for the socialist economy $[7,8,9]$.

A striking example of this form of economic interaction in the agro-industrial complex is the agricultural consumer cooperation. Modeling of the process of forms of production and economic interactions within the framework of the cooperative movement proceeds from the following methodological provisions (Fig. 1):

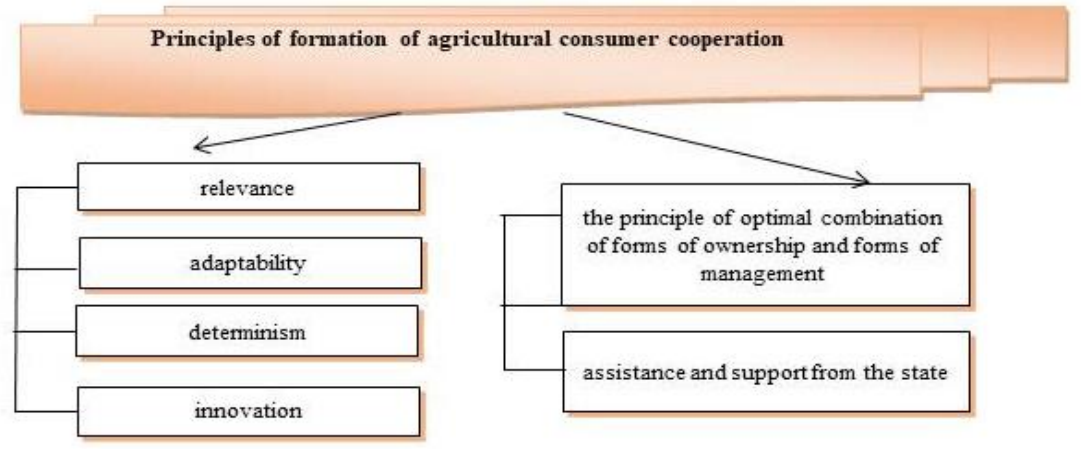

Fig. 1. Principles of development of agricultural consumer cooperation in the agro-industrial complex of Russia. Source: developed by the authors. 
- the principle of adequacy to the nature of creation and the basic values of functioningthis principle means that the implementation of production and economic activities within the framework of a cooperative should be based on its own potential capabilities inherent in this process, as well as material, moral and spiritual values, including: cooperative ethics, flexibility, competitiveness, business competence, human needs. The renunciation of" moral and spiritual roots " during the transition to market rails is associated with the loss of experience in organizing various forms of cooperation in Russian agriculture,

- adaptability-is based on the fact that the progressive development of various forms of management in the agro-industrial complex through the system of cooperation should take into account the objective realities occurring in the national and global economy, changing and adapting to the prevailing forms of ownership, preserving their unique values and assimilating the rational elements of the dominant organizational and legal forms. Currently, these are large agricultural holding structures,

- the principle of determinism involves the identification of causal relationships between different forms of management within the framework of cooperation, in which the cooperative advantages are: developed logistics infrastructure, multi-sectoral nature of activities, the development of communication links in rural areas,

- the principle of innovation is associated with the search for rational forms of coordination of intersectoral relations in economic systems based on the use of an effective system of professional management. In the world practice, this principle of cooperation development is implemented through the theory of "agency relations", in which the functions of public and professional management are clearly regulated. In addition, this principle involves solving economic problems through professional management: determining the optimal structure of production, the organizational structure of the cooperative, using planning tools, technological - improving the efficiency of using available resources, introducing resource-saving technologies, social - developing social infrastructure in rural areas, improving the quality of life of the population, increasing household income $[10,11,12]$.

In the successful development of small farms in the agricultural sector has a special role to the principle of optimal combination of forms of ownership and management forms, which determines the optimal structure of the agricultural sector, represented by the ratio of dynamic proportions between Agroholding large groups, small and medium-sized agribusinesses, state unitary enterprises. The proportions may vary depending on time and regional specifics, taking into account its sectoral structure, the level of food selfsufficiency, the nature-exploiting nature, and the availability of labor resources $[13,14,15]$.

Studies have shown that at the present stage of development of the Russian agricultural economy, characterized by the sanctions regime and the trends of the new economic reality, there is a formation of a new agricultural structure, proportional changes of which strengthen the position of large agricultural holding structures, stimulating the development of the small-format sector. According to our forecast estimates, based on the methods of trend modeling and mathematical statistics, in the medium term for the period up to 2025 . There will be no global changes in the current structure of the agricultural sector of the Russian economy. This fact is confirmed by the dynamics of the forecast values of the quadratic coefficient of relative structural shifts in the context of individual categories of farms (Fig. 2), despite the decrease in the analyzed indicator. 


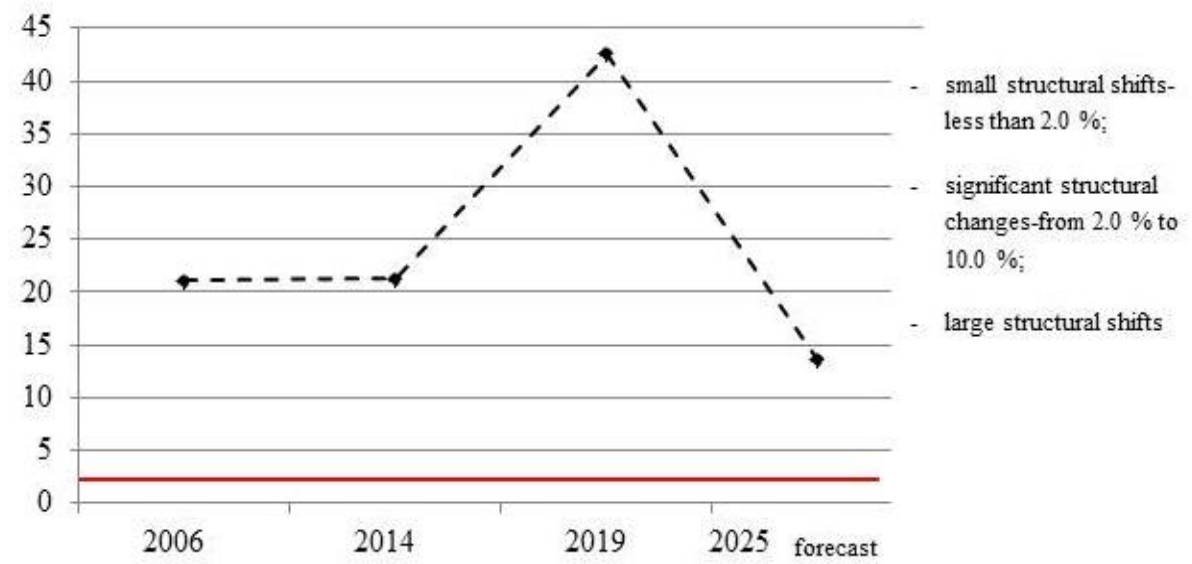

Fig. 2. Forecast estimates of the quadratic coefficient of relative structural shifts in the context of individual categories of farms until 2025. Source: developed by the authors.

Predictive estimates of the quadratic coefficient of relative structural shifts are expected to be in the range of $10.0 \%$ or more. Thus, in order to maintain the established trajectory of successful development of the small-format sector of the economy, in particular peasant (farm) farms, it is necessary not only to maintain, but also to strengthen measures of state support for the agricultural sector of the economy in this direction. The proposed measures will not only stimulate the development of small agribusiness, ensuring the sustainable functioning of agricultural sectors, but will also help to stabilize the situation in the rural hinterland, equalizing the income and employment of rural residents.

The influence of the state on the creation of favorable external economic conditions for small businesses should, in turn, be based on the principles of state regulation based on the project approach to management.

Currently, the development of agricultural cooperation is a priority of the state agrarian policy, as evidenced by the Decree of the President of the Russian Federation of 07.05.2018 no. 204 "On national goals and strategic objectives development of the Russian Federation for the period up to 2024" under which the priority national project "Creation of system of support of farmers and development rural cooperation". The purpose of this project is to determine the strategic trajectory of the development of the agricultural sector of the economy in modern economic conditions. The focus is on state support for entrepreneurial initiatives in agribusiness, which should become, by analogy with countries with developed markets, the engine of growth of agricultural production in the country, stimulating employment of households, increasing the income of private households and the formation of the middle class in the rural hinterland.

In particular, on the example of the implementation of the National project "Creation of system of support of farmers and development rural cooperation", we have developed a scientifically based integrated model of development of small forms of farming in rural areas through a system of agricultural cooperatives based on the project approach in the management of agricultural production, based on the experiences of the leaders in this direction, involving private farms in commodity production and aims to increase the income level of rural residents (Fig.3).

The management tools of the three-level model of development of agricultural consumer cooperatives based on the principles of project management: "settlement district - region" not only provides control and coordination of all levels of the system 
through the provision of grant support and tax benefits, but also creates an infrastructure for the sale of cooperative products.

At the settlement level, the coordinators are the heads of municipalities, who work with the population, form an initiative group, and inform small agribusiness about the benefits of developing cooperation. It should be noted that in the conditions of the new economic reality, without a private initiative that takes into account local peculiarities and traditions, it is impossible to develop cooperation "from above", based only on successful foreign experience and the experience of other regions.

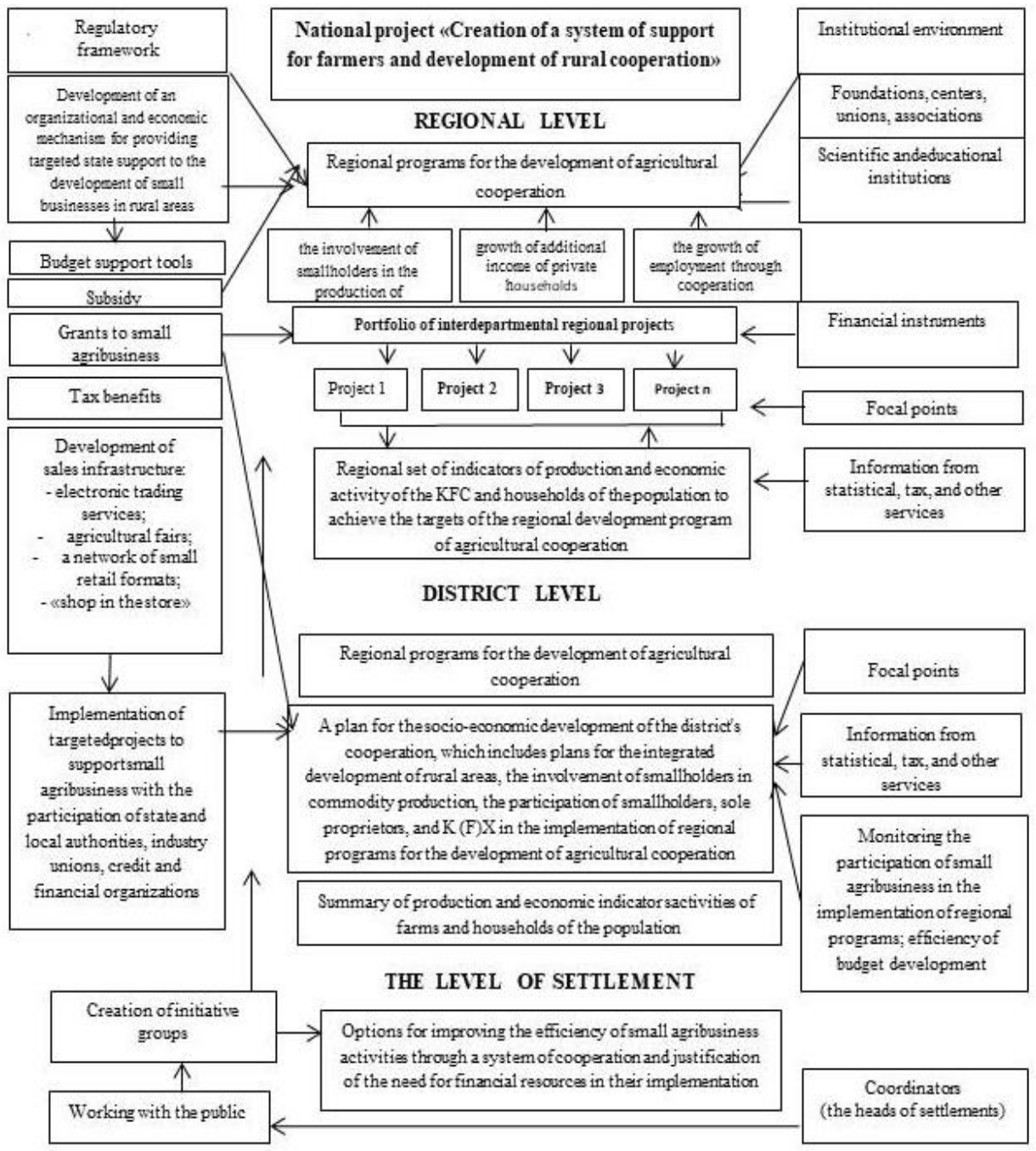

Fig. 3. Model of the formation of the system of agricultural cooperation in Russia based on the principles of project management. Source: developed by the author based on the research materials.

At the district level, with the help of successfully functioning consultation and coordination centers, in cooperation with the settlement coordinators, tasks are solved to select landmarks for further development, and information support is provided.

At the regional level, a portfolio of projects is being formed, including interdepartmental ones, which allows to actively involve the population's farms in commodity production. 


\section{Conclusion}

The proposed organizational and economic mechanism for allocating budget funds in agricultural production sectors based on project management will contribute to the development of a technological platform that allows us to develop areas of interaction not only between agricultural producers and state authorities at all levels, but also between credit and financial organizations, universities, scientific institutions, industry unions and associations, and transform the market relations of economic entities with each other. At the same time, industry unions and associations, in cooperation with the authorities, can initiate the development of a portfolio of priority projects, a mechanism for allocating resources, documenting the main stages of design, training personnel, and implementing software.

\section{References}

1. A.F. Maximov, Economics, labor, and management in agriculture 6(39), 69-75 (2018)

2. N.N. Lipatova, Intelligence. Innovation. Investment 1, 43-50 (2020) doi: $10.235198 / 2077-7175-2020-1-43$

3. O.A. Kholodov, Fundamental and applied research of the cooperative sector of the economy 1, 127-137 (2020)

4. M.N. Suray, Zh.N. Dibrova, O.A. Sagshina, B.L. Orlov, Food Processing: Techniques and Technology 48(1), 680-688 (2018) doi: 10.21603/2074-9414-2018-1-172-183

5. T. Yanina, Agroindustrial complex: economy and management 3, 44-50 (2017)

6. L.N. Usenko, Y.G. Chernysheva, V.A. Guzey, O.M. Todorova, A.M. Usenko, International journal of trade and global markets 2-3, 160-167 (2017) doi: 10.1504/ijtgm.2017.086074

7. M. Slozhenkina, I. Gorlov, M. Kholodova, O. Kholodov, O. Shakhbazova, D. Mosolova, AGRITECH-III-2020 IOP Conf. Series: Earth and Environmental Science 548 (2020) doi:10.1088/1755-1315/548/8/082037

8. A. Tkach, M. Radieva, V. Kolomiiets, Espacios 40(22), 223-228 (2019)

9. A.A. Maksaev, E.P. Bagryantseva, V.Yu. Dianova, N.V. Yatsevich, A.V. Tkach, Frontier Information Technology and Systems Research in Cooperative Economics. "Studies in Systems, Decision and Control" Heidelberg, 383-394 (2021) doi: 10.1007/978-3-030-57831-2_40

10. P.I. Gochiyaeva, A.B. Urusova, Fundamental Research 5-1, 106-110 (2016)

11. I. Ushachev, N. Zhukov, V. Eremeev, Economics of agricultural and processing enterprises 10, 2-8 (2017)

12. S. Podgorskaya, A. Podvesovsky, R. Isaev, Control Sciences 5, 49-59 (2019) doi: http://doi.org/10.25728/pu.2019.5.5

13. O. Isaeva, M. Kabanenko, A. Chistyakov, L. Dubrova, N. Filin, E3s Web of Conferences 175, 13004 (2020) doi: 10.1051/e3sconf/202017513022

14. V. Uzun, N. Shagaida, Z. Lerman, Land Use Policy 83, 475-487 (2019) doi: /10.1016/j.landusepol.2019.02.018

15. M.Y. Veselovsky, M.A. Izmailova, A.V. Bogoviz, S.V. Lobova, A.N. Alekseev, Quality - access to success 19(162), 60-66 (2018) 